\title{
Simultaneous Voltammetric Determination of Acetaminophen and Isoniazid (Hepatotoxicity-Related Drugs) Utilizing Bismuth Oxide Nanorod Modified Screen-Printed Electrochemical Sensing Platforms
}

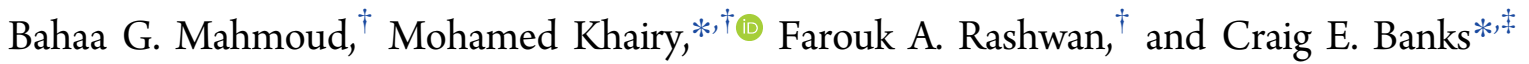 \\ ${ }^{\dagger}$ Chemistry Department, Faculty of Science, Sohag University, 82524 Sohag, Egypt \\ ${ }^{\ddagger}$ Faculty of Science and Engineering, Manchester Metropolitan University, Chester Street, Manchester M1 5GD, United Kingdom
}

Supporting Information

ABSTRACT: To overcome the recent outbreaks of hepatotoxicity-related drugs, a new analytical tool for the continuously determination of these drugs in human fluids is required. Electrochemical-based analytical methods offer an effective, rapid, and simple tool for on-site determination of various organic and inorganic species. However, the design of a sensitive, selective, stable, and reproducible sensor is still a major challenge. In the present manuscript, a facile, one-pot hydrothermal synthesis of bismuth oxide $\left(\mathrm{Bi}_{2} \mathrm{O}_{2.33}\right)$ nanostructures (nanorods) was developed. These $\mathrm{BiO}$ nanorods were cast onto mass disposable graphite screen-printed electrodes (BiO-SPEs), allowing the ultrasensitive determination of acetaminophen (APAP) in the presence of its common interference isoniazid (INH), which are both found in drug samples. The simultaneous electroanalytical sensing using BiO-SPEs exhibited strong electrocatalytic activity toward the sensing of APAP and INH with an enhanced analytical signal (voltammetric peak) over that achievable at unmodified (bare) SPEs. The electroanalytical sensing of APAP and INH are possible with accessible linear ranges from 0.5 to $1250 \mu \mathrm{M}$ and 5 to $1760 \mu \mathrm{M}$ with limits of

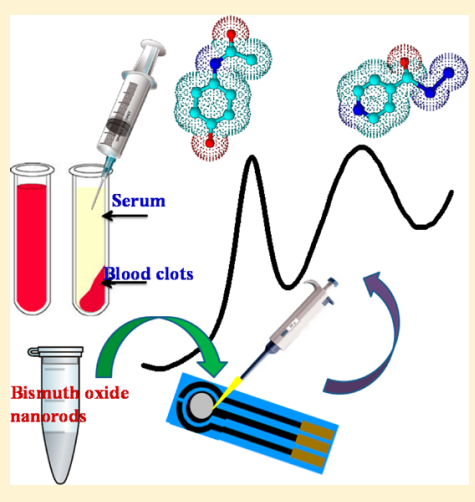
detection $(3 \sigma)$ of $30 \mathrm{nM}$ and $1.85 \mu \mathrm{M}$, respectively. The stability, reproducibility, and repeatability of BiO-SPE were also investigated. The BiO-SPEs were evaluated toward the sensing of APAP and INH in human serum, urine, saliva, and tablet samples. The results presented in this paper demonstrate that BiO-SPEs sensing platforms provide a potential candidate for the accurate determination of APAP and INH within human fluids and pharmaceutical formulations.

$\mathrm{H}$ epatotoxicity implies chemical-driven liver damage and the liver acts as the central organ for metabolism of virtually every foreign substance (i.e., drugs). ${ }^{1}$ More than 900 drugs and herbs have been reported to cause severe liver disease and drugs account for $20-40 \%$ of all instances of fulminant hepatic failure. Approximately $75 \%$ of the idiosyncratic drug reactions result in liver transplantation or death. ${ }^{2}$ Drug-induced liver disease is responsible for 5\% of all hospital admissions and $50 \%$ of all acute liver failures in western countries. ${ }^{3}$ Therefore, physicians must be vigilant in identifying drug-related hepatic injury because early detection can reduce the severity of induced hepatotoxicity. Knowledge of the commonly implicated drugs is essential in clinical diagnosis. In the United States, approximately 2000 cases of acute liver failure occur annually and nearly $60 \%$ of these are caused by acetaminophen or idiosyncratic drug reactions. ${ }^{4}$ Development of an analytical tool for accurate determination of acetaminophen (APAP) and its interferences has a significant importance not only in clinical diagnosis but also for quantity control of their pharmaceutical formulations.

Acetaminophen, APAP ( $N$-acetyl- $p$-aminophenol) is known as Paracetamol or Tylenol and is one of the most widely antipyretic and analgesic drugs these days. It is an extremely weak acid $\left(\mathrm{p} K_{\mathrm{a}}=9.7\right)$ and is, therefore, essentially un-ionized at physiological $\mathrm{pH}$ values. It is commonly used as a safe and effective painkiller associated with headache, backache, arthritis, and postoperative pain. It has also been used for reduction of cough, cold, and fevers symptoms. ${ }^{5}$ The analgesic-antipyretic effect of APAP is similar to aspirin, but APAP is normally preferred, especially for the patients who are sensitive to acetylsalicylic acid. $^{6}$ The mechanism of action of APAP to relieve pain is linked to inhibition of prostaglandin synthesis in the central nervous system and relieves fever by sedating hypothalamic heat-regulating center. ${ }^{7}$ Single doses of APAP shows analgesic activity in a variety of acute pain syndromes without any side effects; however, overdoses ( $4.0 \mathrm{~g} /$ daily) are now the most common cause of acute liver failure, which may progress to death. Therapeutic concentration levels in plasma is between 10 and $25 \mu \mathrm{g} / \mathrm{mL}$, however, its toxicity concentration level is higher than $200 \mu \mathrm{g} / \mathrm{mL}(\approx 1.33 \mathrm{mM})$. It is therefore important to develop an analytical technique to determine acetaminophen in pharmaceutical dosages and human fluids accurately. A variety of analytical methods such as titrimetry, ${ }^{8}$ $\mathrm{UV} /$ vis spectrophotometry, ${ }^{9}$ flow-injection, ${ }^{10}$ high performance liquid chromatography (HPLC), ${ }^{11}$ chemiluminescence, ${ }^{12}$ capil-

Received: December 27, 2016

Accepted: January 6, 2017

Published: January 6, 2017 
lary electrophoresis (CE), ${ }^{13}$ and electrochemical techniques ${ }^{14-16}$ have been recently reported. While, improving the analytical method in terms of sensitivity, stability, repeatability, and selectivity are essential for human health and security. ${ }^{17}$

Isoniazid (isonicotinoyl hydrazine, INH) is an antibacterial drug available as more than $300 \mathrm{mg}$ tablets for oral administration. It is one of effective tuberculostatic drugs widely used for prevention and treatment of tuberculosis due to restriction of mycobacterium strains ${ }^{18,19}$ and is an essential and indispensable basic remedy for tuberculosis. However, it is associated with hepatotoxicity and peripheral neuropathy while slow acetylators may be at increased risk of toxicity. The toxicity can occur with the acute ingestion of as little as $1.5 \mathrm{~g}$ (10.9 $\mathrm{mM}$ ). Moreover, hydrazine was produced during the isoniazid metabolism not only inducing hepatotoxicity with inflammation but also might lead to death. ${ }^{20}$ The Public Health Service Surveillance Study examined 13838 patients treated with INH in the U.S.A.; there were eight deaths among 174 cases of hepatitis. Furthermore, some antipyretic drugs like APAP should be combined with INH to control fever during the course of disease. This combination enhances drug-drug interactions, ultimately affecting their bioavailability and pharmacokinetic behaviors. Such interaction might also increase the extent of bioactive drug resulting in its toxic effects or decrease it to subtherapeutic levels in blood that may lead to antimicrobial resistance. The pretreatment with INH could increase the APAP-induced hepatic necrosis score by $85 \% .^{21}$ Therefore, the people taking INH and APAP are at risk of APAP-toxicity. ${ }^{22}$ The patients treated with INH should be carefully monitored and interviewed periodically every month intervals. HPLC, ${ }^{23}$ spectrophotometry, ${ }^{24}$ chemiluminescence, ${ }^{25}$ $\mathrm{CE}^{26}$ and electrochemical technique ${ }^{27,28}$ have been reported recently for determination of $\mathrm{INH}$. Although electrochemical methods offer fast response, easy handling, and low operating cost, there is only one literature report detailing the simultaneous determination of APAP and INH using thionine-immobilized multiwalled carbon nanotube modified carbon paste electrode. ${ }^{29}$ However, the cost-effective, portability, and difficulty to use such electrodes leads us to explore a new generation of screen-printed electrodes in a form of a point-of-care sensor.

Herein, we explored the simultaneous voltammetric determination of APAP and its common interference of INH using $\mathrm{BiO}$ nanostructure-modified screen-printed electrodes (SPEs). One-pot hydrothermal synthesis of $\mathrm{BiO}$ nanostructures has been developed for the first time. The dispersed $\mathrm{BiO}$ nanorods are simply drop-casted onto SPE surfaces after which the sensors are ready to be utilized. The BiO-SPEs are found to exhibit greater electrocatalytic activity, stability, and reproducibility for the simultaneous determination of APAP and INH in aqueous $\mathrm{pH} 2$ buffer solution over unmodified (bare) SPEs. The suggested BiO-SPE electrochemical sensing platform was successfully employed to detect the concentration of APAP and $\mathrm{INH}$ in human fluids and pharmaceutical formulations.

\section{EXPERIMENTAL SECTION}

All chemicals were used without any further purification. Bismuth nitrate $\left(\mathrm{Bi}\left(\mathrm{NO}_{3}\right)_{3}, 99.9 \%\right)$ was obtained from SigmaAldrich Company Ltd. Acetaminophen was kindly supplied by Glopal Napi Pharmaceutical Co. (6th of October, Egypt) and Isoniazid purchased from BDH Co., Ltd. All experiments were performed in Britton Robinson (BR) buffer solutions containing $0.05 \mathrm{M}$ of each boric acid, phosphoric acid, and acetic acid and 0.1 M sodium hydroxide was added to reach the required $\mathrm{pH}$ value of the solution.

Synthesis of Bismuth Oxide Nanostructures. The hydrothermal synthesis of bismuth oxide nanorods has been developed using bismuth nitrate $\mathrm{Bi}\left(\mathrm{NO}_{3}\right)_{3}$ and ammonium hydroxide $\left(\mathrm{NH}_{4} \mathrm{OH}, 28 \%\right)$ as starting precursors without using any further additives or template-directing agents. In our synthesis approach, $2.42 \mathrm{~g}$ of $\mathrm{Bi}\left(\mathrm{NO}_{3}\right)_{3}$ was dissolved in 50.0 $\mathrm{mL}$ of acidified deionized water. The transparent solution of $\mathrm{Bi}\left(\mathrm{NO}_{3}\right)_{3}$ was introduced into a $100.0 \mathrm{~mL}$ Teflon-lined stainless steel autoclave. Then, $\mathrm{NH}_{4} \mathrm{OH}$ solution was introduced until a white precipitate was formed. The solution mixture has a $\mathrm{pH}$ value of 2.2 . The autoclave was sealed and placed in an oven at $160{ }^{\circ} \mathrm{C}$ for $12 \mathrm{~h}$ for hydrothermal treatment after which was then allowed to cool at room temperature. After the hydrothermal process, a white precipitate was collected and rinsed several times with ethanol/water mixture to remove the remaining agents before being dried at $50{ }^{\circ} \mathrm{C}$. Finally, the large yield of bismuth oxide nanorods was formed by calcination at $300{ }^{\circ} \mathrm{C}$ for $3 \mathrm{~h}$.

Fabrication of Bismuth Oxide Modified ScreenPrinted Electrode. The SPEs were fabricated in-house with appropriate stencil using a DEK 248 screen-printing machine (DEK, Weymouth, U.K.). These electrodes have been used extensively in previous studies For their fabrication, first, a carbon-graphite ink formulation (product code C2000802P2; Gwent Electronic Materials Ltd., U.K.) was screen-printed onto a polyester (Autostat, $250 \mu \mathrm{m}$ thickness) flexible film (denoted throughout as standard-SPEs); these electrodes have been used extensively in other work. ${ }^{17,30-37}$ This layer was cured in a fan oven at $60{ }^{\circ} \mathrm{C}$ for $30 \mathrm{~min}$. Next, a silver/silver chloride reference electrode was included by screen-printing $\mathrm{Ag} / \mathrm{AgCl}$ paste (product code C2040308D2; Gwent Electronic Materials Ltd., U.K.) onto the polyester substrates and a second curing step was undertaken where the electrodes were cured at $60{ }^{\circ} \mathrm{C}$ for $30 \mathrm{~min}$. Finally, a dielectric paste (product code D2070423D5; Gwent Electronic Materials Ltd., U.K.) was then printed onto the polyester substrate to cover the connections. After a final curing at $60{ }^{\circ} \mathrm{C}$ for $30 \mathrm{~min}$, these SPEs are ready to be used. These SPEs have been reported previously and shown to exhibit a heterogeneous electron transfer (HET) rate constant, $k^{\circ}$, of about $10^{-3} \mathrm{~cm} \mathrm{~s}^{-1}$, as measured using the $\left[\mathrm{Ru}\left(\mathrm{NH}_{3}\right)_{6}\right]^{3+/ 2+}$ redox probe.

The SPEs were modified with $\mathrm{BiO}$ nanostructures by a simple drop-casting process. The $\mathrm{BiO}$ suspension was prepared by dispersing $5.0 \mathrm{mg}$ of $\mathrm{BiO}$ powder in $5.0 \mathrm{~mL}$ of deionized water and then sonicated for $10 \mathrm{~min}$. A total of $5.0 \mu \mathrm{L}$ of the $\mathrm{BiO}$ suspension was dropped onto the SPE surface and left it to dry in an oven at $50{ }^{\circ} \mathrm{C}$ for $30 \mathrm{~min}$.

Real Sample Analysis. Fresh human blood ( $5 \mathrm{~mL}$ ) was collected from healthy volunteers in the hospital of Sohag University, with the aliquot of the sample collected in a test tube. The collected blood sample was kept at room temperature for $30 \mathrm{~min}$ and then centrifuged for $5 \mathrm{~min}$ at $3500 \mathrm{rpm}$. Finally, the supernatant serum sample was collected in a new test tube and stored at $4{ }^{\circ} \mathrm{C}$ in a refrigerator when not in use. The APAP and INH in low, medium and high concentration levels have been spiked into blood serum sample. Then, the recovery test was carried out by spiking of APAP and INH in serum sample into $10 \mathrm{~mL}$ electrochemical cell containing pH 2.0 B.R buffer and differential pulse voltammetry (DPV) was recorded. A standard addition method was used to determine the APAP and INH concentrations. 
The applicability of BiO-SPEs was also tested in several real samples (human blood, urine, saliva and pharmaceutical tablets). APAP and INH were injected to the real samples and left for $1.0 \mathrm{~h}$, stored at $4{ }^{\circ} \mathrm{C}$ in a refrigerator. For human blood, the sample was centrifuged for $5 \mathrm{~min}$ at $3500 \mathrm{rpm}$. The supernatant serum sample containing APAP and INH was collected in a new test tube and the $\mathrm{pH}$ was adjusted to $\mathrm{pH} 2$ using hydrochloric acid. Then, $100 \mu \mathrm{L}$ of serum samples was dropped onto three electrode configuration cell of $\mathrm{BiO}$-SPEs working electrode. DPV was utilized, and the standard addition method was used to determine the APAP and INH concentration.

For urine and saliva samples, $300 \mu \mathrm{L}$ of saliva or urine samples was also injected with APAP and INH and stored at 4 ${ }^{\circ} \mathrm{C}$ in the refrigerator for $1.0 \mathrm{~h}$. Then, the sample solution was adjusted to $\mathrm{pH} 2$ using $\mathrm{HCl}$. A total of $100 \mu \mathrm{L}$ of adjusted saliva or urine samples was dropped onto the working electrode of the BiO-SPEs and DPV was utilized.

A total of 10 tablets of APAP (Paracetamol, $500 \mathrm{mg}$ ) and INH (Isocid forte, $200 \mathrm{mg}$ ) pharmaceutical formulations were accurately weighed and finely ground in a mortar. A chosen amount of these powders were transferred into a $100 \mathrm{~mL}$ volumetric flask. About $20 \mathrm{~mL}$ of ethanol was added, swirled, and sonicated for $5 \mathrm{~min}$. The volume of the sample was completed to the mark and finally filtered using fine filter paper. The first portion of the filtrate was rejected. A specific volume of the stock solution of the drugs was diluted with deionized water to obtain the suitable concentration. A $100 \mu \mathrm{L}$ of a particular concentration of APAP and INH solutions were diluted by B.R. buffer $\mathrm{pH} 2$ and dropped onto the BiO-SPEs and compared with the standard concentrations of APAP and INH drugs. The concentrations of APAP and INH were measured by DPV method.

Characterization of Bismuth Oxide Nanostructures. The morphology of the bismuth oxide sample was investigated using field emission scanning electron microscopy (FE-SEM, JEOL model 6500). The bismuth oxide powder was ground and fixed onto a specimen stub using double-sided carbon tape. To obtain high-resolution micrographs, a $10 \mathrm{~nm}$ Pt film was coated on the bismuth oxide using anion sputtering (Hitachi E1030 ) at room temperature. The SEM was operated at $15 \mathrm{keV}$ to obtain high-resolution SEM images. Further, transmission electron microscopy (TEM) of $\mathrm{BiO}$ sample was performed using a JEOL JEM microscope model 2100. TEM was conducted at an acceleration voltage of $200 \mathrm{kV}$ to obtain a lattice resolution of $0.1 \mathrm{~nm}$. TEM images were recorded using a CCD camera. The $\mathrm{BiO}$ sample was dispersed in ethanol solution by using an ultrasonic bath, and then dropped on a copper grid. Prior to inserting the samples into the TEM column, the grid was vacuum-dried for $20 \mathrm{~min}$.

Wide-angle powder X-ray diffraction (XRD) was performed by X-ray diffractometer (Model FW 1700 series, Philips, Netherlands) using with monochromatic $\mathrm{CuK}_{\alpha}$ radiation $(\lambda=$ $1.54 \AA$ ), employing a scanning rate of $0.06^{\circ} / \mathrm{min}$ and $2 \theta$ ranges from $20^{\circ}$ to $80^{\circ}$. The diffraction data were analyzed using PDF software released in 1996.

The textural surface properties and pore size distribution was determined by $\mathrm{N}_{2}$ adsorption/desorption isotherms at $77 \mathrm{~K}$ with a BELSORP36 analyzer (JP. BEL Co., Ltd.). The specific surface area $\left(S_{\mathrm{BET}}\right)$ was calculated using the BrunauerEmmett-Teller (BET) method with multipoint adsorption data from the linear segment of the $\mathrm{N}_{2}$ adsorption isotherm. The pore size distribution was determined from the analysis of desorption branch of isotherm using Barrett-Joyner-Halenda (BJH) method.

The voltammetric measurements were carried out using Autolab $302 \mathrm{~N}$ potentiostat/galvanostat workstation and data was controlled by NOVA software version 1.11.2 for Windows 7. Experiments were performed using $3 \mathrm{~mm}$ bismuth oxide modified graphite screen-printed working electrode, platinum counter electrode, and saturated calomel electrode (SCE) reference electrode.

\section{RESULTS AND DISCUSSION}

Physicochemical Characterization of the Bismuth Oxide Nanostructures. Bismuth oxide is an important metal oxide semiconductor that has been intensively investigated due to excellent optical and electrical properties such as wide band gap, high refractive index, high dielectric permittivity, and good photoconductivity. ${ }^{38,39}$ Owing to these unique features, it has been widely used in many applications such as schottky barrier solar cells, sensor technology, varistors, optical coatings, photovoltaic cells, microwave integrated circuits, and transparent ceramic glass manufacturing. ${ }^{38,39}$ Control over the morphology, size, crystallinity, and surface composition of bismuth oxide nanostructures can effectively alter its physicochemical characteristics. Herein, a simple, onepot hydrothermal synthesis of $\mathrm{BiO}$ nanostructures has been carried out by adjusting the $\mathrm{pH}$ of acidic solution of bismuth nitrate by ammonium hydroxide solution until a white precipitate was formed. After which, calcination of obtained white powder at $300{ }^{\circ} \mathrm{C}$ for $3.0 \mathrm{~h}$ was performed.

Although the particle morphology, composition, and size are crucial factors for metal oxide nanostructures applicability, ${ }^{30,30-42}$ very little literature has reported its ability to control the size and morphology of bismuth oxide $\left(\mathrm{Bi}_{2} \mathrm{O}_{3}\right)$ nanostrucures. ${ }^{38,39,43}$ Figure 1A shows the SEM micrograph of

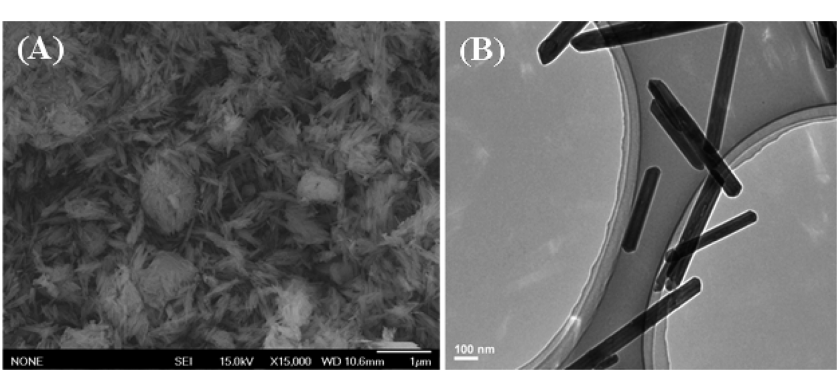

Figure 1. (A) FE-SEM and (B) TEM images of $\mathrm{BiO}$ nanostructures prepared via a simple hydrothermal treatment.

bismuth oxide sample synthesized by a facile one-pot hydrothermal method without any additives. The SEM image exhibits highly dispersed and nanosized bismuth oxide with rod-like morphology. The average diameter of bismuth oxide nanorods is about $50 \mathrm{~nm}$ with a length of $400 \mathrm{~nm}$. Further, TEM image (Figure 1B) shows dispersed $\mathrm{BiO}$ nanorods with an average diameter of $50 \mathrm{~nm}$ and a length of about 300-400 nm. Significantly, our synthesis conditions provide a facile and template-free method for fabrication of highly crystalline bismuth-rich bismuth oxide nanostructures without any agglomeration.

The specific surface area and porosity of the $\mathrm{BiO}$ nanorods were investigated by using $\mathrm{N}_{2}$ adsorption/desorption isotherms. Figure 2 shows a representative $\mathrm{N}_{2}$ adsorption/ desorption isotherm measured at $77 \mathrm{~K}$ and distribution of 

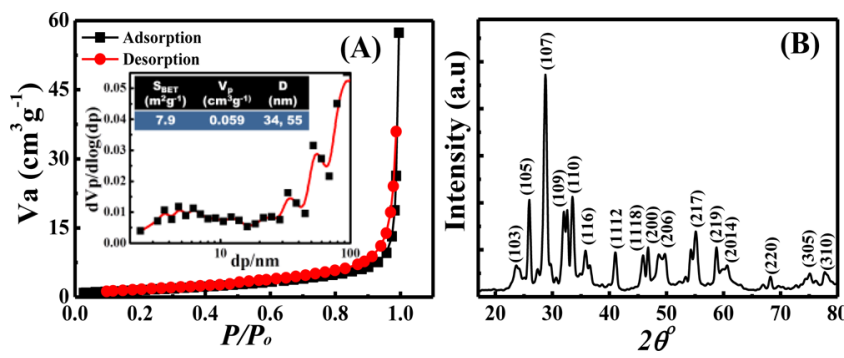

Figure 2. (A) Nitrogen adsorption/desorption isotherm and its corresponding $\mathrm{BJH}$ pore distribution curve; (B) Typical X-ray powder diffraction pattern of the $\mathrm{BiO}$ nanostructures.

pore diameter for the synthesized $\mathrm{BiO}$ sample. The $\mathrm{N}_{2}$ isotherm can be categorized as type IV with a distinct $\mathrm{H} 3$ hysteresis loop was observed in the range of $0.5-1.0 \mathrm{P} / \mathrm{P}_{0}$, which was characteristic of macro-/ meso-porous materials. The $S_{\mathrm{BET}}$ specific surface area was calculated to be $7.9 \mathrm{~m}^{2} \mathrm{~g}^{-1}$. Further, the $\mathrm{BiO}$ nanorods contained small mesopores with average diameter about 5,34 , and $55 \mathrm{~nm}$, determined by using the Barret-Joyner-Halenda (BJH) method (Figure 2B). The formation of the lower pore size was probably related to the pores present inside the nanorods, which were formed between primary crystallites. In turn, the higher pore size may be related to the voids between the nanorod particles. Such multi-modal porous texture of $\mathrm{BiO}$ nanorods is very important in electrochemical sensors because it provides enhanced surface area with macro-/mesopores. These significant features are the key factors for controlling the diffusion pathway of analytes and alter the solution/electrode interface. Furthermore, the crystal structure of the bismuth oxide powder was characterized using $\mathrm{XRD}$ and is shown in Figure 2B. Different diffraction peaks have been indexed with corresponding (hkl) values using JCPDS data file (27-0051) indicating the nanocrystalline structure of the bismuth oxide. The XRD patterns also confirmed preferential growth of tetragonal phases of $\mathrm{Bi}_{2} \mathrm{O}_{2.33}$. Interestingly, the XRD shows stoichiometric changes due to oxygen loss. The slight excess of $\mathrm{Bi}$ atoms over oxygen atoms in the tetragonal crystal might offer enhanced electron conductivity for better electrochemical performance.

Electrochemical Characterization of Bismuth Oxide Nanostructures. To explore the electrochemical performance of (BiO-SPE), the redox probe of $\mathrm{K}_{3} \mathrm{Fe}(\mathrm{CN})_{6}$ has been studied. Figures 3 and $\mathrm{S} 1$ show the cyclic voltammetric curves of $\mathrm{BiO}$ modified and bare/unmodified screen printed-electrode in $2 \times$ $10^{-4} \mathrm{~mol} \mathrm{~L}^{-1} \mathrm{~K}_{3}\left[\mathrm{Fe}(\mathrm{CN})_{6}\right] / 0.1 \mathrm{~mol} \mathrm{~L}^{-1} \mathrm{KCl}$ recorded over a range of voltammetric scan rates. In both cases, the peak
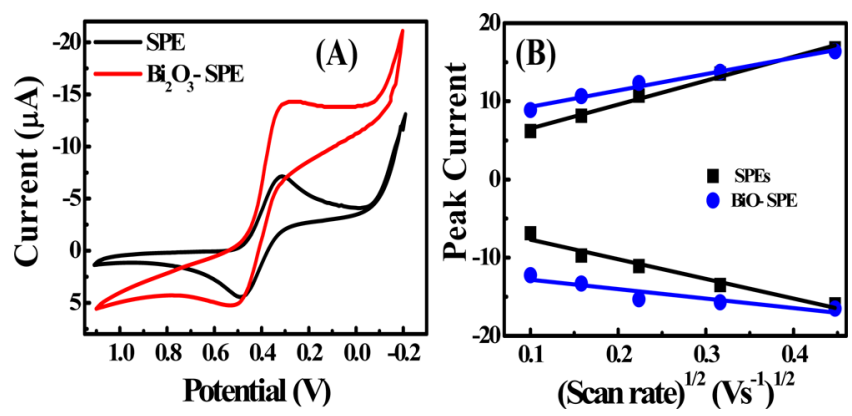

Figure 3. (A) Cyclic voltammetric curves of SPE and BiO-SPEs in 0.1 $\mathrm{M} \mathrm{KCl}$ containing $2 \times 10^{-4} \mathrm{M}$ potassium ferricyanide. (B) Cyclic voltammetric peak current analysis at various scan rates. heights were increased with increasing the potential scan rate as well as they are linearly correlated with the square root of the scan rates in the range of $10-200 \mathrm{mV} / \mathrm{s}$ (as shown in Figure 3B), suggesting a diffusion controlled process of reactants at the electrode surface. Comparing the $\mathrm{CV}$ curves at $10 \mathrm{mV} / \mathrm{s}$, it was found that the peak current ratio $\left(I_{\mathrm{pc}} / I_{\mathrm{pa}}\right)$ is equal to 1.1 for the unmodified SPEs, while the BiO-SPEs exhibit a $I_{\mathrm{pc}} / I_{\mathrm{pa}}$ equal to 1.37. Therefore, the BiO-SPEs may be claimed to promote electron transfer reaction better than the unmodified SPE does. Moreover, the peak separation was slightly increased to $179 \mathrm{mV}$ at the $\mathrm{BiO}$-SPEs compared to $170 \mathrm{mV}$ for unmodified SPEs, which is due to the electrostatic repulsion between $[\mathrm{Fe}$ $\left.(\mathrm{CN})_{6}\right]^{3-}$ and $\mathrm{BiO}$ nanorod surface. This behavior suggests that the $\mathrm{BiO}$ surface is more negatively charged, in agreement with the behavior observed for Titanate nanotubes. ${ }^{40}$ The results show in Figure 3 that the $\mathrm{BiO}$ nanorods have enhanced the electrochemical signal/performance of the graphite screenprinted electrode by an order of $\sim 2$ times, which might be attributed to the free bismuth atoms on the surface of $\mathrm{BiO}$ nanoparticles that facilitated the electron transfer process and/ or an increase in the electrochemical surface area (i.e., the $\mathrm{BiO}$ kinetics dominate). ${ }^{30}$

Electrochemical Behavior of APAP and INH. The voltammetric behavior of APAP and INH were investigated on $\mathrm{BiO}$-SPEs because the isoniazid was considered as an important drug interferes with APAP in pharmaceuticals. Figure S2 illustrates the cyclic voltammograms of $75 \mu \mathrm{mol} \mathrm{L} \mathrm{L}^{-1}$ APAP and $75 \mu \mathrm{mol} \mathrm{L}{ }^{-1}$ INH obtained in B.R. Buffer solution ( $\mathrm{pH}$ 2.0) on unmodified and $\mathrm{BiO}$ modified SPEs. $\mathrm{BiO}$ nanorods showed an efficient electrocatalytic activity for the oxidation of APAP and INH molecules compared to bare SPEs. In order to explore the efficiency of $\mathrm{BiO}$ nanorods, different metal oxide nanostructure materials and bismuth-based materials have been synthesized and used for determination of APAP and INH drugs. $\mathrm{NiO},{ }^{40} \mathrm{CuO},{ }^{30} \mathrm{CdO},{ }^{44} \mathrm{MgO},{ }^{45} \mathrm{Bi}_{2} \mathrm{~S}_{3},{ }^{46} \mathrm{Bi}_{12} \mathrm{NiO}_{19}{ }^{47}$ and bulky $\mathrm{Bi}_{2} \mathrm{O}_{3}$ have been investigated (as shown in Figure $\mathrm{S} 3$ ). Interestingly, $\mathrm{BiO}$ nanorods-SPEs show high sensitivity and stability as well as good peak potential separation in the determination of APAP and INH molecules. Figure 4A shows
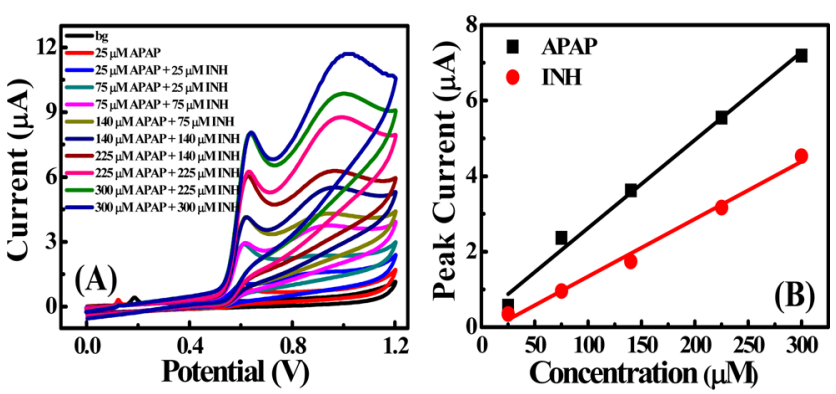

Figure 4. (A) Cyclic voltammetric curves observed at $\mathrm{BiO}$ nanorods modified SPEs for successive additions of APAP and INH into B.R buffer $\mathrm{pH}$ 2. (B) Corresponding cyclic voltammetric peak current analysis of APAP and INH additions at scan rate $50 \mathrm{mV} \mathrm{s}^{-1}$.

cyclic voltammetry of successive additions individually of APAP and $\mathrm{INH}$ in BR buffer $\mathrm{pH} 2.0$ at scan rate of $50 \mathrm{mVs}^{-1}$ on $\mathrm{BiO}$ SPEs. As it can be seen, APAP and INH exhibit well-defined oxidation peaks around 0.64 and $1.02 \mathrm{~V}$, respectively. The peak potentials difference of about $0.38 \mathrm{~V}$ (vs SCE) between both oxidation peaks clearly allows the simultaneous determination of APAP and INH without any interference. Of interest is the 
voltammetric peak current response of APAP and INH on the $\mathrm{BiO}-\mathrm{SPE}$ linearly correlates with their concentrations up to 300 $\mu \mathrm{mol} \mathrm{L}{ }^{-1}$, as shown in Figure 4B.

Next attention was turned to explore the effect of $\mathrm{pH}$ upon the electrochemical signals of APAP and INH, since the selection of suitable medium is very important for simultaneous electrochemical responses of APAP and INH. Figure S4 shows the cyclic voltammetric curves of $100 \mu \mathrm{M}$ of APAP and $100 \mu \mathrm{M}$ $\mathrm{INH}$ onto BiO-SPEs in different $\mathrm{pH}$ values in different $\mathrm{pH}$ values. Moreover, effect of solution $\mathrm{pHs}$ on the $\mathrm{CV}$ curves for $50 \mu \mathrm{mol} \mathrm{L}{ }^{-1} \mathrm{APAP}$ and $50 \mu \mathrm{mol} \mathrm{L}{ }^{-1}$ INH onto BiO-SPEs also presented. With increasing the $\mathrm{pH}$ value, the oxidation potentials of APAP and INH were shifted to less positive potential values and the oxidation peak of INH interferes with oxidation peak of APAP. This result indicates that, the $\mathrm{pH} 2$ is the suitable medium for simultaneous determination of APAP and INH. A plot of peak potential $(E)$ versus $\mathrm{pH}$, as shown in Figure $\mathrm{S} 4 \mathrm{D}$, was constructed where a linear range with gradient of $43 \mathrm{mV} / \mathrm{pH}$ and $64 \mathrm{mV} / \mathrm{pH}$ for APAP and INH, respectively, were observed (For APAP; $E / V=0.043 \mathrm{Ep}(\mathrm{V}) / \mathrm{pH}+0.55 \mathrm{~V}$, $R^{2}=0.95$; For INH; $E / V=0.064 \mathrm{Ep}(\mathrm{V}) / \mathrm{pH}+0.83 \mathrm{~V}, R^{2}=$ $0.98)$. These values are close to that of Nernstian slope (59 $\mathrm{mV} / \mathrm{pH}$ ), which related to transfer an equal number of protons and electrons and likely to be in agreement with the literature. ${ }^{5,29,50-59}$ Therefore, we supposed that the oxidation of APAP and INH at BiO-SPEs likely involves $2 \mathrm{e}^{-} / 2 \mathrm{H}^{+}$transfer processes, as shown in Scheme 1. In APAP, it was observed

Scheme 1. Oxidation Mechanisms of APAP and INH at BiOSPEs
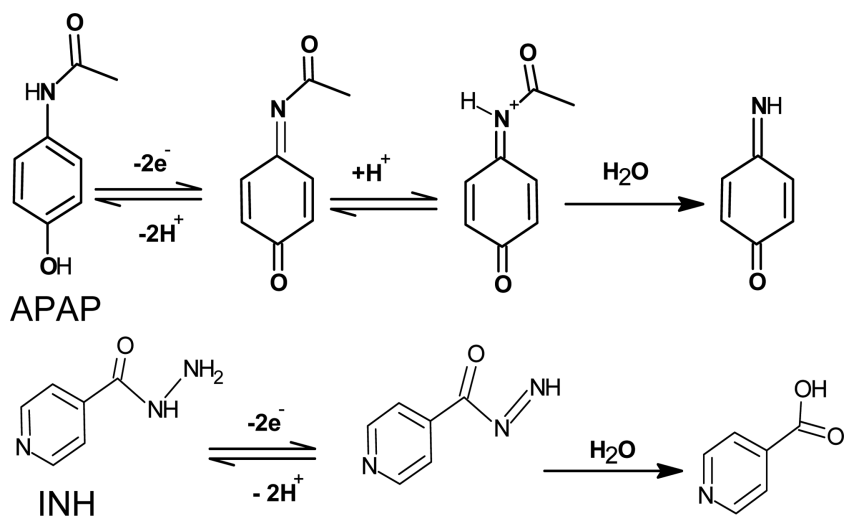

that, the peak current of APAP was decreased in alkaline solutions. The $\mathrm{p} K_{\mathrm{a}}$ value APAP in solution is about 9.7, above this value the APAP was existed in deprotonated form which exhibit a net negative charge. Such negative charge will be repulsed with the negative charge of the BiO-SPE surface. Moreover, the deprotonated APAP form is likely to be more soluble in aqueous solution than its neutral species; hence, the amount of diffused APAP to BiO-SPEs surface is much lower than its fraction in the solution. Therefore, the acidic medium is highly desirable for oxidation of APAP on BiO-SPEs. The oxidation of APAP includes transfer of $2 \mathrm{e}^{-} / 2 \mathrm{H}^{+}$to form quinone-like structure followed by hydrolysis of the acetamide functional group to produce $p$-aminophenol (Scheme 1). Further, the $\mathrm{p} K_{\mathrm{a}}$ value of INH is about 4.84 and therefore, protonated form of isoniazid will be also very important in the electrostatic attraction with negatively charged $\mathrm{BiO}$ nanorods. In alkaline medium, the oxidation peak was splitted to oneelectron coupled with one-proton reaction process for each of these two peaks. The oxidation of INH on BiO-SPEs is undergoing transfer of $2 \mathrm{e}^{-} / 2 \mathrm{H}^{+}$and subsequently hydrolyses to Isonicotinic acid. The optimal voltammetric response in Figure S4C suggested that B.R. buffer $\mathrm{pH} 2$ is a suitable supporting electrolyte for determination of APAP and INH in real samples.

Next, the effect of scan rates upon the electrochemical oxidation behaviors of APAP and INH was explored in B.R. buffer $\mathrm{pH}$ 2.0. Figure 5 shows the cyclic voltammetric profiles
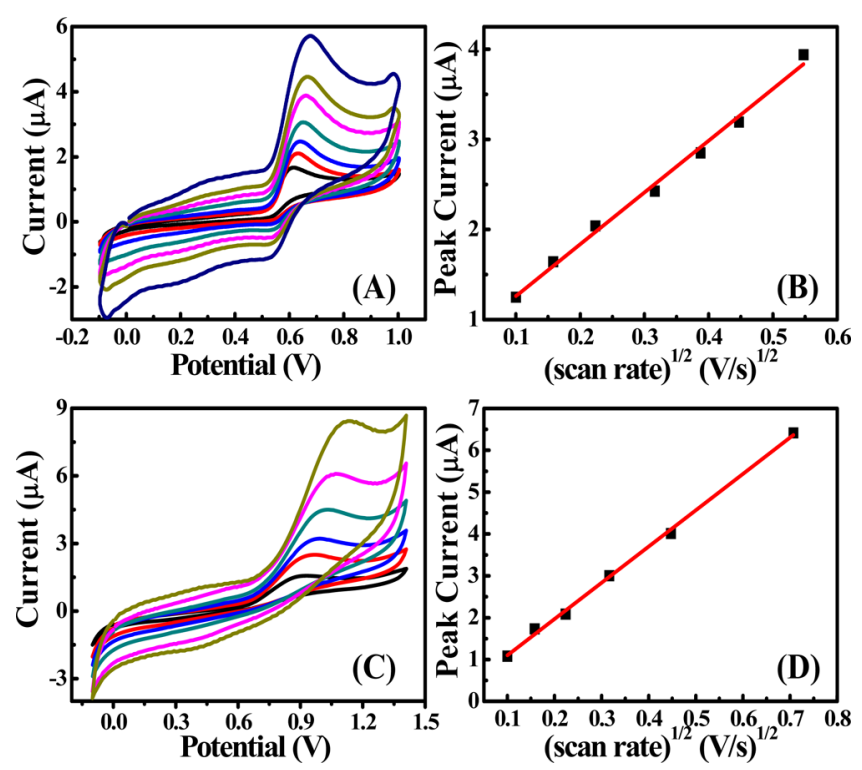

Figure 5. Effect of scan rate on cyclic voltammetric curves of $100 \mu \mathrm{M}$ of APAP (A and B) and $100 \mu \mathrm{M}$ of INH (C and D) observed at $\mathrm{BiO}$ nanorods modified SPEs in B.R. buffer $\mathrm{pH} 2$.

of $100 \mu \mathrm{mol} \mathrm{L} \mathrm{L}^{-1}$ APAP and $100 \mu \mathrm{mol} \mathrm{L}{ }^{-1} \mathrm{INH}$ in $\mathrm{pH} 2$ in different scan rate in the range of $10-300 \mathrm{mV} \mathrm{s}^{-1}$. No reduction peak has been observed in the cyclic voltammograms of INH. However, the intensity of APAP reduction peak becomes significant at higher scan rates. Meanwhile, there was a positive shift of peak potential with the increase of scan rates. The analysis of peak height against the square root of scan rate was found to be linear indicating a diffusional controlled processes (for APAP; $I_{\mathrm{pa}} / \mu \mathrm{A}=5.74 \mu \mathrm{A}\left(\mathrm{V} \mathrm{s}^{-1}\right)^{-1 / 2}+0.68 \mu \mathrm{A}$, $R^{2}=0.992$, For INH; $I_{\mathrm{pa}} / \mu \mathrm{A}=8.67 \mu \mathrm{A}\left(\mathrm{V} \mathrm{s}^{-1}\right)^{-1 / 2}+0.23 \mu \mathrm{A}$, $\left.R^{2}=0.997\right)$. Moreover, the linear relationship of $\log \left(I_{\mathrm{pa}}\right)$ and $\log v$ can be expressed as follows; For APAP: $\log I_{\mathrm{pa}}=0.33 \log$ $v+0.73$, For INH: $\log I_{\mathrm{pa}} / \mu \mathrm{A}=0.45 \log v+0.925$. The slope values are very close to the theoretical value of 0.5 , which clearly indicates a diffusion controlled electrode process (rather than a thin layer effect). From the above results, the electrooxidation of APAP and INH can be described as in Scheme 1.

Electrochemical Determination of APAP and INH. Next, DPV was employed to investigate the sensitivity of BiOSPEs in terms of linear ranges and the detection limits for the APAP and INH drugs. The DPV experiments were recorded using the following parameters; step potential $0.01 \mathrm{~V}$, modulation potential $0.025 \mathrm{~V}$, modulation time $0.05 \mathrm{~s}$, interval time $0.2 \mathrm{~s}$, scan rate $50 \mathrm{mV} \mathrm{s}^{-1}$, deposition time $5 \mathrm{~s}$, and equilibrium time 5 s. Figure 6 displays the DPV responses of the electrochemical oxidation of APAP and INH using BiOSPEs in $\mathrm{pH} 2.0$ of BR buffer under the optimized working conditions. The peak height was increased with continuous additions of APAP and INH solutions. For APAP, two linear relationships were established (as shown in Figure 6B) in the 

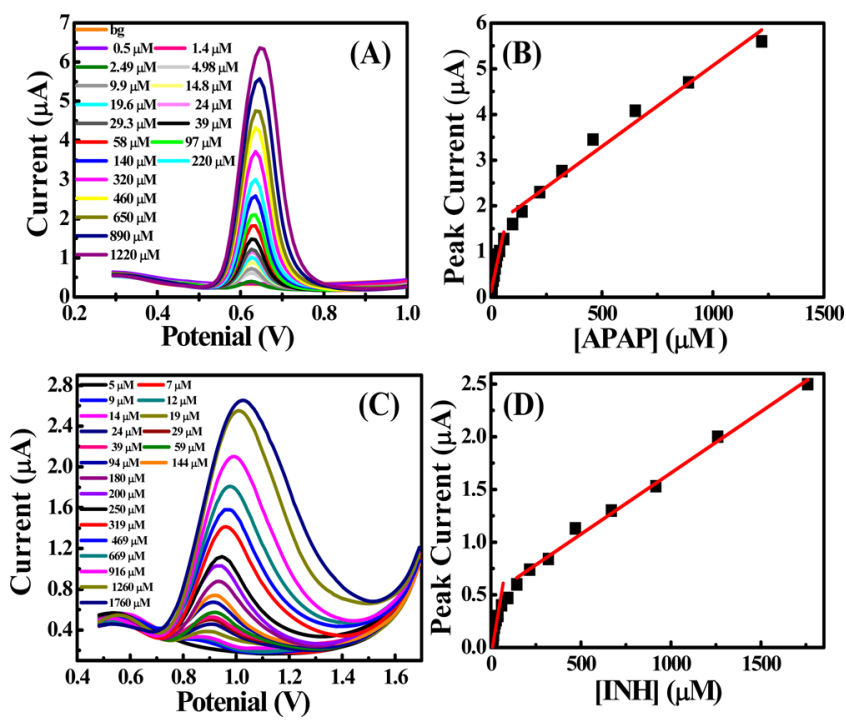

Figure 6. DPV responses from successive additions of APAP (A) and INH (C) into B.R. buffer $\mathrm{pH} 2$ at $\mathrm{BiO}$ nanostructures modified SPEs. (B, D) Typical calibration plots corresponding to APAP and INH additions up to $1800 \mu \mathrm{M}$. DPV parameters: step potential $0.01 \mathrm{~V}$, modulation potential $0.025 \mathrm{~V}$, modulation time $0.05 \mathrm{~s}$, interval time $0.2 \mathrm{~s}$, scan rate $50 \mathrm{mV} \mathrm{s}^{-1}$, deposition time $5 \mathrm{~s}$, and equilibrium time 5 s.

range of 0.5 to $97 \mu \mathrm{mol} \mathrm{L}-1$ and 140 to $1250 \mu \mathrm{mol} \mathrm{L}^{-1}$ as $I_{\mathrm{p}}$ $(\mu \mathrm{A})=0.027 \mu \mathrm{A} \mu \mathrm{M}^{-1}+0.06 \mu \mathrm{A}\left(R^{2}=0.997\right)$ and $I_{\mathrm{p}}(\mu \mathrm{A}) \stackrel{\mathrm{p}}{=}$ $0.0034 \mu \mathrm{A} \mu \mathrm{M}^{-1}+1.64 \mu \mathrm{A}\left(R^{2}=0.98\right)$, respectively. As well as two linear segments of INH were also presented (as shown in Figure $6 \mathrm{D})$ in the range of $5-100 \mu \mathrm{mol} \mathrm{L}^{-1}$ and $144-1760$ $\mu \mathrm{mol} \mathrm{L}{ }^{-1}$ as $I_{\mathrm{p}}(\mu \mathrm{A})=0.008 \mu \mathrm{A} \mu \mathrm{M}^{-1}-0.009 \mu \mathrm{A}\left(R^{2}=0.99\right)$ and $I_{\mathrm{p}}(\mu \mathrm{A})=0.0012 \mu \mathrm{A} \mu \mathrm{M}^{-1}+0.49 \mu \mathrm{A}\left(R^{2}=0.98\right)$, respectively. Based on the first linear fitting equations of APAP and INH, the limits of detection were calculated to be $30 \mathrm{nmol}$ $\mathrm{L}^{-1}$ and $1.85 \mu \mathrm{mol} \mathrm{L}{ }^{-1}$, respectively. The superior performance of the BiO-SPEs suggests a promising platform for the electrochemical determination of APAP and INH in real samples.

As mentioned previously, simultaneous determination of APAP and INH was studied in different $\mathrm{pH}$ values, and B.R. buffer $\mathrm{pH} 2.0$ was selected as a suitable supporting electrolyte solution. DPV experiments for simultaneous determination of APAP and INH are carried out in $\mathrm{pH} 2.0$, as represented in Figure 7. DPV of successive additions of APAP in the presence of $50 \mu \mathrm{mol} \mathrm{L} \mathrm{L}^{-1} \mathrm{INH}$ revealed two well-separated and distinct oxidation peaks of APAP and INH were observed (Figure 7A). Interestingly, there was no significant change of the voltammetric response of INH with consequence additions of APAP. The calibration curve of APAP was shown in Figure $7 \mathrm{~B}$ with the linear relationship from 10 to $210 \mu \mathrm{mol} \mathrm{L}{ }^{-1}$ with a linear equation; $I_{\mathrm{p}}(\mu \mathrm{A})=0.02 \mu \mathrm{A} \mu \mathrm{M}^{-1}+0.083 \mu \mathrm{A}\left(R^{2}=\right.$ 0.997). While, Figure $7 \mathrm{C}$ shows DPV of successive additions of INH in the presence of $50 \mu \mathrm{mol} \mathrm{L}{ }^{-1}$ APAP. As can see from the voltammograms, relatively the current response of APAP does not effect by addition of INH even at high concentrations. A linear calibration curve for INH additions was presented in Figure 7D; $I_{\mathrm{p}}(\mu \mathrm{A})=0.007 \mu \mathrm{A} \mu \mathrm{M}^{-1}+0.937 \mu \mathrm{A}\left(R^{2}=0.97\right)$. The limits of detection of APAP and INH were calculated based on these linear fitting equations to be $37 \mathrm{nmol} \mathrm{L}^{-1}$ and $1.61 \mu \mathrm{mol} \mathrm{L}{ }^{-1}$, respectively. These results synergistically proved the feasibility of simultaneous determination and distinguished
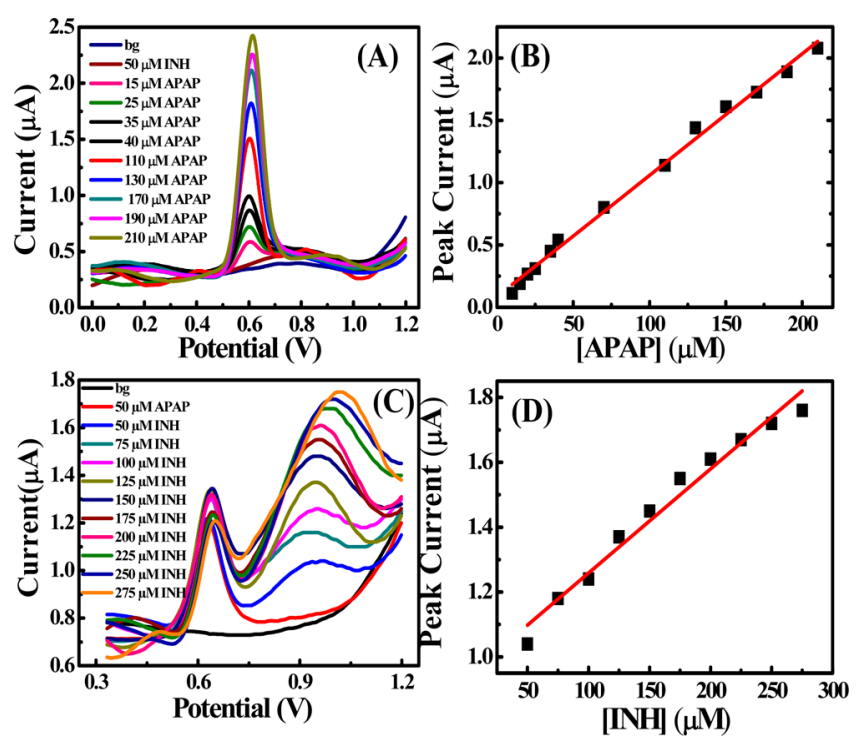

Figure 7. (A) DPV curves from successive addition of APAP in presence $50 \mu \mathrm{M} \mathrm{INH}$ and (B) corresponding peak current as a function of APAP concentrations. (C) DPV curves for successive addition of INH in presence $50 \mu \mathrm{M}$ APAP and (D) corresponding peak current as a function of INH concentration. DPV parameters: step potential $0.01 \mathrm{~V}$, modulation potential $0.025 \mathrm{~V}$, modulation time $0.05 \mathrm{~s}$, interval time $0.2 \mathrm{~s}$, scan rate $50 \mathrm{mV} \mathrm{s}^{-1}$, deposition time $5 \mathrm{~s}$, and equilibrium time $5 \mathrm{~s}$.

electrochemical sensing performance of $\mathrm{BiO}-\mathrm{SPE}$ to APAP and INH drugs as shown in Table 1.

Repeatability of BiO-SPEs for APAP and INH Determination. Screen-printed electrode is a favorable approach in electroanalytical chemistry because it provides a low-cost, single-shot, disposable, yet highly reproducible and reliable platform for electrochemical measurement of the target analyte. However, the sensitivity and selectivity are a major challenge. Therefore, the modification of SPEs with active nanomaterials or biorecognition events has been developed. The reproducibility of $\mathrm{BiO}$-SPEs was investigated by using the same $\mathrm{BiO}$ SPEs for five repetitive measurements of $50 \mu \mathrm{mol} \mathrm{L}-1$ APAP and $100 \mu \mathrm{mol} \mathrm{L}{ }^{-1}$ INH under the optimum conditions. The relative standard deviation was calculated to be $0.27 \%$ and $0.08 \%$ for APAP and $\mathrm{INH}$, respectively. Furthermore, BiOSPEs show not only reproducible signal on the same electrode but also with separately employed SPEs. Three electrodes were examined in the presence of $50 \mu \mathrm{mol} \mathrm{L}{ }^{-1}$ APAP and $100 \mu \mathrm{mol}$ $\mathrm{L}^{-1} \mathrm{INH}$ under the same conditions. The relative standard deviation was calculated to be $1.7 \%$ and $2.1 \%$ for APAP and INH drugs, respectively. These results revealed that $\mathrm{BiO}$ nanorods are promising materials in electrochemical determination of APAP and INH in real samples.

Analysis of Real Samples. To verify the applicability of a $\mathrm{BiO}-\mathrm{SPE}$ sensor, the recovery experiment for determination of $\mathrm{APAP}$ and INH in a human serum environment was performed as in Characterization of Bismuth Oxide Nanostructures. Before DPV determination, the APAP and INH were spiked into human serum and left it for $30 \mathrm{~min}$ in fridge at $4{ }^{\circ} \mathrm{C}$. Then, these spiked samples were added to $10 \mathrm{~mL}$ electrochemical cell containing B. R. buffer $\mathrm{pH}$ 2.0. The concentrations of APAP and INH were determined by standard addition protocol. The results were summarized and listed in Table 2 . The recovery experiment for human serum samples demonstrated that the 
Table 1. Comparisons of the Proposed Bismuth Oxide-SPEs with Previous Reported Electrochemical Methods for APAP and INH Determinations

\begin{tabular}{|c|c|c|c|c|}
\hline electrode & target molecule & linear range $(\mu \mathrm{M})$ & LOD $(\mu \mathrm{M})$ & ref \\
\hline thionine immobilized & APAP & $0.1-100$ & 0.05 & 29 \\
\hline MWCNT/CPE & INH & $1-100$ & 0.8 & \\
\hline EGR,ZnO/GCE & APAP & $0.02-10$ & 33 & 48 \\
\hline tyrosine/GCE & INH & $25-125$ & 6.93 & 49 \\
\hline $\mathrm{Fe}_{3} \mathrm{O}_{4} / \mathrm{PDDA} / \mathrm{GR} / \mathrm{GCE}$ & APAP & $0.1-100$ & 0.037 & 50 \\
\hline AuNP-MWCNT/GCE & INH & $0.2-10$ & 0.0003 & 51 \\
\hline MIPRu-AuNP-MCNT/GCE & INH & $0.1-110$ & 0.08 & 52 \\
\hline $\mathrm{OMC} / \mathrm{GC}$ & INH & $0.1-370$ & 0.084 & 53 \\
\hline ERGO/GCE & INH & $2-70$ & 0.17 & 54 \\
\hline RGO-Au/GCE & INH & $10-1000$ & 0.01 & 55 \\
\hline (MWCNT-chit/GCE) & INH & $10-100$ & 0.055 & 56 \\
\hline GR/GCE & APAP & & 0.032 & 57 \\
\hline $\mathrm{Au}$ and glutamic acid/CPE & APAP & $0.05-70$ & & 58 \\
\hline GCE & APAP & $4-100$ & 0.369 & 59 \\
\hline $\mathrm{TiO}_{2}-\mathrm{GR} / \mathrm{GCE}$ & APAP & $1-100$ & 0.21 & 5 \\
\hline \multirow[t]{2}{*}{ BiO-SPEs } & APAP & $0.5-97$ & 0.03 & this work \\
\hline & INH & $5-100$ & 1.85 & \\
\hline
\end{tabular}

Table 2. Determination of APAP and INH Added in Human Serum Samples Using DPV ${ }^{a}$

\begin{tabular}{|c|c|c|c|c|c|c|}
\hline \multirow[b]{2}{*}{$\begin{array}{l}\text { blood } \\
\text { serum }\end{array}$} & \multicolumn{2}{|c|}{ added $(\mu \mathrm{M})$} & \multicolumn{2}{|c|}{ detected $(\mu \mathrm{M})$} & \multicolumn{2}{|c|}{ recovery $(\%) \pm \mathrm{SD}^{b}$} \\
\hline & APAP & INH & APAP & INH & APAP & INH \\
\hline sample 1 & 10 & 40 & 9.8 & 37.2 & $98 \pm 1.94$ & $93 \pm 3.15$ \\
\hline & 15 & 60 & 15.3 & 62.4 & $102 \pm 2.04$ & $104 \pm 4.17$ \\
\hline sample 2 & 10 & 40 & 10.2 & 39.2 & $102 \pm 1.49$ & $98 \pm 2.44$ \\
\hline & 15 & 60 & 15.4 & 55.2 & $102.7 \pm 1.75$ & $92 \pm 4.34$ \\
\hline
\end{tabular}

${ }^{a}$ Each sample was measured three times, $n=3 .{ }^{b}$ Relative standard deviation.

BiO-SPE electrochemical sensing platforms held great promise for reliable and sensitive application in the clinical analysis.

Moreover, to explore the applicability of BiO-SPEs in simultaneous and sensitive determination of APAP and INH, the recovery experiments were performed in human blood, urine, and saliva samples. As explained in the Experimental Section, the APAP and INH were injected to the human fluid samples and stored at $4{ }^{\circ} \mathrm{C}$ in a refrigerator. After $1.0 \mathrm{~h}$, the human blood was centrifuged for $5 \mathrm{~min}$ at $3500 \mathrm{rpm}$. The supernatant serum sample containing APAP and INH was collected in a new test tube and the $\mathrm{pH}$ was adjusted to $\mathrm{pH} 2$ by $\mathrm{HCl}$. A $100 \mu \mathrm{L}$ of treated serum samples was dropped onto
BiO-SPEs cell, DPV was utilized and the standard addition method was used to determine the APAP and INH concentrations. On other hand, $300 \mu \mathrm{L}$ of urine or saliva samples was injected by APAP and INH and stored at $4{ }^{\circ} \mathrm{C}$ in refrigerator for $1.0 \mathrm{~h}$. The sample solution was adjusted to $\mathrm{pH} 2$ using $\mathrm{HCl}$ and dropped onto $\mathrm{BiO}$-SPEs and DPV was utilized. Further, the APAP and INH were determined in pharmaceutical dosage. The concentrations or "recoveries" of APAP and INH were obtained. As shown in Figure S5 and Table 3, BiOSPEs are promising candidates in determination of APAP and INH in different matrix samples.

\section{CONCLUSIONS}

A simple and one-pot hydrothermal synthesis of bismuth-rich bismuth oxide $\left(\mathrm{Bi}_{2} \mathrm{O}_{2.33}\right)$ nanorods has been developed for the first time. The bismuth oxide powder casted onto screenprinted electrode mutually facilitates the electron transfer and mass transport as well as electrocatalytic activity toward oxidation of APAP and INH drugs. The unique properties of bismuth oxide in terms of porosity, surface area, and nanoscale dimension offered a remarkable decrease in overvoltage and improved electrochemical response of APAP and INH drugs. Furthermore, the BiO-SPEs were applied for the determination of APAP and INH in human serum with satisfying results,

Table 3. Recovery of APAP and INH in Different Real Samples Measured by DPV Using a Three-Electrode BiO-SPEs Configuration Cell ${ }^{a}$

\begin{tabular}{|c|c|c|c|c|c|c|}
\hline \multirow[b]{2}{*}{ sample } & \multicolumn{2}{|c|}{ added $(\mathrm{mM})$} & \multicolumn{2}{|c|}{ detected $(\mathrm{mM})$} & \multicolumn{2}{|c|}{ recovery $(\%) \pm \mathrm{SD}^{b}$} \\
\hline & APAP & INH & APAP & INH & APAP & INH \\
\hline human blood & 0.25 & 0.50 & 0.213 & 0.475 & $85 \pm 4.04$ & $95 \pm 2.10$ \\
\hline \multirow[t]{3}{*}{ urine samples } & 2.0 & 2.0 & 2.2 & 1.96 & $111 \pm 3.09$ & $98 \pm 1.04$ \\
\hline & 1.0 & 4.0 & 1.09 & 3.96 & $109 \pm 4.34$ & $99 \pm 2.50$ \\
\hline & 0.40 & 1.50 & 0.43 & 1.45 & $108 \pm 3.75$ & $97 \pm 2.30$ \\
\hline \multirow[t]{2}{*}{ saliva samples } & 2.0 & 2.0 & 2.08 & 2.04 & $104 \pm 3.2$ & $102 \pm 2.01$ \\
\hline & 1.0 & 3.0 & 1.08 & 3.15 & $108 \pm 2.1$ & $105 \pm 1.02$ \\
\hline \multirow[t]{2}{*}{ pharmaceutical tablets } & 0.25 & 0.25 & 0.245 & 0.253 & $98 \pm 2.08$ & $101.2 \pm 3.2$ \\
\hline & 0.1 & 0.1 & 0.103 & 0.099 & $103 \pm 3.05$ & $99 \pm 3.6$ \\
\hline
\end{tabular}

${ }^{a}$ Each sample was measured three times, $n=3 .{ }^{b}$ Relative standard deviation. 
indicating that $\mathrm{BiO}-\mathrm{SPEs}$ can be a promising electrode material for on-site determination of APAP and INH drugs.

\section{ASSOCIATED CONTENT}

\section{S Supporting Information}

The Supporting Information is available free of charge on the ACS Publications website at DOI: 10.1021/acs.analchem.6b05130.

CVs of potassium ferricyanide solution on $\mathrm{SPE}$ and $\mathrm{BiO}$ SPE at different scan rates, CVs of APAP and INH in different $\mathrm{pHs}$, and relation between peak potential and $\mathrm{pH}$ of solution. DPV response of real sample measurements (PDF).

\section{AUTHOR INFORMATION}

\section{Corresponding Authors}

*E-mail: mohamed.khairy@science.sohag.edu.eg. Tel.: +(02) 01092099116.

*E-mail: c.banks@mmu.ac.uk.

\section{ORCID ${ }^{\circ}$}

Mohamed Khairy: 0000-0002-8579-0093

\section{Notes}

The authors declare no competing financial interest.

\section{ACKNOWLEDGMENTS}

The authors acknowledge funding from a British Council Institutional Link Grant (No. 172726574, ID: 18435) for the support of this research.

\section{REFERENCES}

(1) Russmann, S.; Kullak-Ublick, G. A.; Grattagliano, I. Curr. Med. Chem. 2009, 16, 3041-3053.

(2) Friedman, S. E.; Grendell, J. H.; McQuaid, K. R. Current Diagnosis and Treatment in Gastroenterology; Lang Medical Books/McGraw-Hill: New York, 2003; pp 664-679.

(3) Darvas, F.; Guttman, A.; Dormán, G. Chemical Genomics and Proteomics, 2nd ed.; CRC Press, Taylor \& Francis group, LLC: New York, 2013; p 138.

(4) Lee, W. M. Clin Liver Dis. 2013, 17, 575-586.

(5) Fan, Y.; Liu, J.-H.; Lu, H.-T.; Zhang, Q. Colloids Surf., B 2011, 85, 289-292.

(6) Prabakar, S. J. R.; Narayanan, S. S. Talanta 2007, 72, 1818.

(7) Andersson, D. A.; Gentry, C.; Alenmyr, L.; Killander, D.; Lewis, S. E.; Andersson, A.; Bucher, B.; Galzi, J.-L.; Sterner, O.; Bevan, S.; Högestätt, E. D.; Zygmunt, P. M. Nat. Commun. 2011, 2, 551.

(8) Burgot, G.; Auffret, F.; Burgot, J. L. Anal. Chim. Acta 1997, 343, 125.

(9) Sirajuddin, A. R.; Khaskheli, A.; Shah, M. I.; Bhanger, A.; Niaz, S.; Mahesar, S. Spectrochim. Acta, Part A 2007, 68, 747.

(10) Ruengsitagoon, W.; Liawruangrath, S.; Townshend, A. Talanta 2006, 69, 976.

(11) Selvan, P. S.; Gopinath, R.; Saravanan, V. S.; Gopal, N.; Kumar, S. A.; Periyasamy, K. Asian J. Chem. 2007, 19, 1004-1010.

(12) Zhao, S.; Bai, W.; Yuan, H.; Xiao, D. Anal. Chim. Acta 2006, 559, 195-199.

(13) Capella-Peiro, M. E.; Bose, D.; Rubert, M. F.; Esteve-Romero, J. J. Chromatogr. B: Anal. Technol. Biomed. Life Sci. 2006, 839, 95-101.

(14) Sun, D.; Zhang, H. J. Microchim. Acta 2007, 158, 131-136.

(15) Mingqi, L.; Linhai, J. Electrochim. Acta 2007, 52, 3250.

(16) Kumar, S. A.; Tang, C. F.; Chen, S. M. Talanta 2008, 76, 997.

(17) Cumba, L. R.; Smith, J.; Zuway, K. Y.; Sutcliffe, O. B.; do Carmo, D. R.; Banks, C. E. Anal. Methods 2016, 8, 142.

(18) Byrd, C. B.; Nelson, R.; Elliott, R. C. JAMA 1972, 220, 14711473

(19) Kauffman, G. B. J. Chem. Educ. 1978, 55, 448.
(20) Tafazoli, S.; Mashregi, M.; O’Brien, P. J. Toxicol. Appl. Pharmacol. 2008, 229, 94-101.

(21) Epstein, M. M.; Nelson, S. D.; Slattery, J. T.; Kalhorn, T. F.; Wall, R. A.; Wright, J. M. clin. Br. J. 1991, 31, 139-142.

(22) Murphy, R.; Swartz, R.; Watkins, P. B. Ann. Intern. Med. 1990, 113, 799-800.

(23) Yan, H.; Zhou, Y.; Xie, Q.; Zhang, Y.; Zhang, P.; Xiao, H.; Wang, W.; Yao, S. Anal. Methods 2014, 6, 1530-1537.

(24) Safavi, A.; Karimi, M. A.; Hormozi Nezhad, M. R.; Kamali, R.; Saghir, N. Spectrochim. Acta, Part A 2004, 60, 765-769.

(25) Wu, B.; Wang, Z.; Xue, Z.; Zhou, X.; Du, J.; Liu, X.; Lu, X. Analyst 2012, 137, 3644-3652.

(26) Liu, Y.; Fu, Z.; Wang, L. Luminescence 2011, 26, 397-402.

(27) Si, X.; Jiang, L.; Wang, X.; Ding, Y.; Luo, L. Anal. Methods 2015, 7, 793-798.

(28) Bergamini, M. F.; Santos, D. P.; Zanoni, M. V. B. Bioelectrochemistry 2010, 77, 133-138.

(29) Shahrokhian, S.; Asadian, E. Electrochim. Acta 2010, 55, 666672.

(30) Mahmoud, B. G.; Khairy, M.; Rashwan, F. A.; Foster, C. W.; Banks, C. E. RSC Adv. 2016, 6, 14474-14482.

(31) Smith, J. P.; Metters, J. P.; Irving, C.; Sutcliffe, O. B.; Banks, C. E. Analyst 2014, 139, 389-400.

(32) Kolliopoulos, A. V.; Dimitrios, K.; Kampouris, D. K.; Banks, C. E. Anal. Chem. 2015, 87, 4269-4274.

(33) Smith, J. P.; Metters, J. P.; Khreit, O. I.; Sutcliffe, O. B.; Banks, C. E. Anal. Chem. 2014, 86, 9985-9992.

(34) Metters, J. P.; Kadara, R. O.; Banks, C. E. Analyst 2011, 136, $1067-1076$.

(35) Metters, J. P.; Kadara, R. O.; Banks, C. E. Analyst 2013, 138, 2516-2521.

(36) Khairy, M.; Choudry, N. A.; Oustai, M.; Kampouris, D. K.; Kadara, R. O.; Banks, C. E. ChemPhysChem 2010, 11, 875.

(37) Khairy, M.; Kadara, R. O.; Kampouris, D. K.; Banks, C. E. Anal. Methods 2010, 2, 645.

(38) Liu, L.; Jiang, J.; Jin, S.; Xiab, Z.; Tang, M. CrystEngComm 2011, 13, 2529-2532.

(39) Guenther, G.; Kruis, F. E.; Guillon, O. J. Phys. Chem. C 2014, $118,27010-27019$.

(40) Liu, A.; Wei, M.; Honma, I.; Zhou, H. Anal. Chem. 2005, 77, $8068-8074$

(41) Khairy, M.; El Safty, S. A. Sens. Actuators, B 2014, 193, 644-652.

(42) Khairy, M.; El-Safty, S. A.; Ismael, M.; Kawarada, H. Appl. Catal., B 2012, 123, 162-173.

(43) Song, J- M.; Mao, C.- J.; Niu, H.-L.; Shen, Y.-H.; Zhang, S.-Y. CrystEngComm 2010, 12, 3875-3881. Muruganandham, M.; Amutha, R.; Lee, G.-J.; Hsieh, S.-H.; Wu, J. J.; Sillanpaa, M. J. Phys. Chem. C 2012, 116, 12906-12915.

(44) Jiang, H.; Hu, J.; Li, C.; Gu, F.; Ma, J. CrystEngComm 2010, 12, 1726-1729.

(45) Minami, H.; Kinoshita, K.; Tsuji, T.; Yanagimoto, H. J. Phys. Chem. C 2012, 116, 14568-14574.

(46) Chen, R.; Ho So, M.; Che, C.-M.; Sun, H. J. Mater. Chem. 2005, $15,4540-4545$

(47) Pei, L. Z.; Wei, T.; Lin, N.; Zhang, H. J. Alloys Compd. 2016, 663, 677-e685.

(48) Jiang, L.; Gu, S.; Ding, Y.; Jiang, F.; Zhang, Z. Nanoscale 2014, 6, 207.

(49) Cheemalapati, S.; Devadas, B.; Chen, S.-M.; Ali, M. A.; AlHemaid, F. M. A. Anal. Methods 2014, 6, 6774.

(50) Lu, D. B.; Zhang, Y.; Wang, L.; Lin, S. X.; Wang, C. M.; Chen, X. F. Talanta 2012, 88, 181-186.

(51) Wu, B.; Hou, L.; Zhang, T.; Han, Y.; Kong, C. Anal. Methods 2015, 7, 9121.

(52) Wu, B.; Wang, Z.; Xue, Z.; Zhou, X.; Du, J.; Liu, X.; Lu, X. Analyst 2012, 137, 3644

(53) Yan, X.; Bo, X.; Guo, L. Sens. Actuators, B 2011, 155, 837-842.

(54) Cheemalapati, S.; Palanisamy, S.; Chen, S.-M. Int. J. Electrochem. Sci. 2013, 8, 3953-3962. 
(55) Guo, Z.; Wang, Z. Y.; Wang, H. H.; Huang, G. Q.; Li, M. M. Mater. Sci. Eng., C 2015, 57, 197-204.

(56) Satyanarayana, M.; Reddy, K. K.; Gobi, K. V. Anal. Methods 2014, 6, 3772.

(57) Kang, X.; Wang, J.; Wu, H.; Liu, J.; Aksay, I. A.; Lin, Y. Talanta 2010, 81, 754-759.

(58) Zhang, Y.; Luo, L.; Ding, Y.; Liu, X.; Qian, Z. Microchim. Acta 2010, 171, 133-138.

(59) Engin, C.; Yilmaz, S.; Saglikoglu, G.; Yagmur, S.; Sadikoglu, M. Int. J. Electrochem. Sci. 2015, 10, 1916-1925. 